\title{
A Qualitative Study of Artificial Intelligence Application Framework in Human Resource Management
}

\author{
S.N. Premnath and A. Arun \\ Christ (Deemed to be University), Lavasa, Pune, India
}

\begin{abstract}
Artificial Intelligence (Al) has grown by leaps and bounds in the past few years making it a necessary tool for organizations all over the world to pave the road to a smart future by entering into its various functions and making it more efficient. However, companies in India have been hesitant and slow to adapt this technology and this hesitation is ever so clearly seen in the Human Resources function of the organization. The Primary purpose of this article is to explore the application, benefits and challenges of integration, and the limitations of $A$ I in HRM within the Indian context. The responses for the study were collected from various Top-level HR Professionals through multiple forms of interviews. The sampling method used was purposive sampling. The research is an exploratory study that uses the data collected through the interviews to identify the various methods in which artificial intelligence is used in the Human Resource function, the problems faced in implementation of the technology and the benefits of using Al. The studyis relevant and beneficial to organisations that seek to enhance the effectiveness and efficiency of their HRM functions by leveraging the power of Al.
\end{abstract}

Keywords: Artificial Intelligence, Human Resource Management, Limitations of Al, Benefits of Al, Recruitment and Selection, Training and Development, Technology

\section{INTRODUCTION}

Human Resources (HR) has evolved steadily as a result of globalization and the immense developments in information technology which has helped it cross over various obstacles that were confining it to be treated as a mere administrative role in the organization (Mellam, Rao \& Mellam, 2015). This growth in the HR functions can be mapped through the constant shifts in its focus. The first phase, during which analysing the impact of HR practices on employees became organization centric. Phase two was when the HR expanded their scope to evaluating complete HR systems over singular HR practices. The final phase saw a paradigm shift in HR when it moved from HR to SHRM as a result of the realization that only the HR could align the goals of the organization to the goals of the personnel successfully (Wright \& Ulrich 2017). However, performing a strategic role is not easy as the most important resource to drive any strategy is information and data. This has nudged HR to progress even further in order to quench the thirst for information and accommodate for the needs and changes of the modern business world that focuses on growing at minimal costs. Today, HR has evolved into a form that is highly driven by technology and data that is constantly collected from employees to further enhance their strategic role. The by-product of this is seen in the form of E-HRM where HR is more of a platform rather than a person (Johnson \& Guetal, 2011). Just like the HR function, technology has also had its fair share of evolution transforming from a simple machine created to reduce human effort to more complex systems capable of doing a lot more than just that. The use of a combination of technologies related to information technology (IT), web-based programs, analytical models, etc., has helped companies deal with their workforce in a highly efficient manner (Oswal \& Narayanappa, 2015). One of the most powerful technologies following the same lineage is Artificial Intelligence (AI).

Although artificial intelligence and human resources may sound like an oxymoron in the sense that people feel its purpose is to replace them, the truth is quite different. Artificial Intelligence alludes to the technological innovation that enables machines to do tasks that would normally require humans owing to their intelligence (Ernst \& Young, 2018). Al complements human intelligence as it relieves employees from indulging in tasks that can be automated forcing them to enhance their knowledge and skills in a manner that will create more value to the organization.

Human Resource functions in companies across the globe have adapted Al into their organizations realizing its limitless potential and applications. Some of the biggest companies in the world such as IBM, Amazon, Google, etc., are using Al incorporated with the HR function to come up with innovative solutions to employee problems concerning HR (Aspan, 2020). A survey conducted by HR.com suggests that the functions where $\mathrm{Al}$ interventions have the greatest potential in HR are - in tracking employee workhours and turnout, analytics and metrics, recruitment and selection, training \& development, and compensation 
(HR.com, 2017). At the same time, it is observed that there is areluctance to invest and adapt Al has also been majorly seen in the HR functions in businesses all over the world as compared to other business functions such as Marketing, Finance, etc (Brin, 2019).

Al in HR within companies functioning in India also have not seen an equal amount of growth and integration.In the HR domain, many professionals are still sceptical about Al as they doubt its ability to produce satisfactory results in areas which they believe predominantly require empathy and intuition (PWC, 2017). HR in many companies in India still believe that employees can only be dealt with effectively through human intervention as many decisions taken by HR in an organization are not just purely driven by data. The focus on aspects such as the ethicality of basing decisions only on Al and other technologies seems to be driving resistance (Desai, 2019). This has led most of the HR functions in India to turn a blind eye to the fact that in such a data driven era where the data is the key to unlocking limitless possibilities a huge amount of data collected from employees is not being put to efficient use.

There has been a dearth of documented studies with regard to the application of Al in human resource function in Indian companies. In this context, this study attempts to explore the opportunities Al holds for the HRM operations from an Indian perspective. This qualitative research has the following objectives:

i. To understand the perception of Human Resource Professionals in Indiatowards Artificial Intelligence.

ii. Understand the current applications and future opportunities of Artificial Intelligence in Human Resource functions in the Indian business context.

iii. To identify the benefits HRs in India are reaping after the integration of Al into theirfunction.

iv. To identify the challenges involved in the implementation of Artificial Intelligence for Human Resource functions.

\section{LITERATURE REVIEW}

\section{ARTIFICIAL INTELLIGENCE AND HUMAN RESOURCE MANAGEMENT}

Artificial Intelligence is a science that aims to replicate aspects of human intelligence such as learning, reasoning, perceiving, critical thinking, etc., using computer programs that are guided by logic (Villani, 2018). The ability of Al to crunch massive volumes of big data and convert it into meaningful information for decision making helps in altering and enhancing user (employee) and candidate experience in organizations for the better (Kapoor, 2020) (Meister, 2019). According to Tom Stachura, IBM, "Al is an accelerator - it allows us the ability to ingest a variety of data and provide context to a decision maker or employee or business leader. It allows us to deliver the right intelligence in the moment and achieve personalization at scale." Unlike other technologies that were designed to increase efficiency while reducing costs, Als are also designed to add value while completing any task (Guenole \& Feinzig, 2018). This ability of Al to integrate easily into the HR function and deliver value is important for HRs because of the transformation in the role of an HR from being a mere support function in an organization to a strategyoriented function that helps in driving the whole organization (Jain, 2014). Al strengthens the transition by amplifying the speed and efficiency of the HR function by taking over the mundane tasks while the personnel move towards fostering unique aspects such as empathy, critical thinking and creativity (Stevenson, 2019). Although Al seems to be able to take over a lot work being done in the HR function it is still a far way from replacing the HR personnel completely because of the persistent need for human intervention while dealing with employees (Davenport, 2019).

\section{ARTIFICIAL INTELLIGENCE IN RECRUITMENT}

$\mathrm{Al}$ is a ground-breaking innovation that helps organizations develop to compete in this era by trading off manpower for increased machine handling with the aim of recruiting potential high-performance candidates for the company (Geetha \& Reddy, 2018). Al has become a necessary tool for recruiters over the past few years with $76 \%$ of recruiters believing that Al will have a significant impact in the recruitment function of HR (Verlinden, 2019). Recruitment is the most dominant function in HR where Al is being used to replace manual candidate screening with Al powered screening in order to shorten this time-consuming process (Folick, 2016). Repetitive and high-volume tasks in recruitment such as screening candidate resumes are being taken over by Al through their innovative machine learning capabilities allowing it to continuously recruit good candidates from a potential pool by comparing the characteristics of the candidates with those of successful current employees (McFadden, 2019; He, 2019). 


\section{ARTIFICIAL INTELLIGENCE IN TRAINING AND DEVELOPMENT}

Organizations need to always ensure that their employees are at the top of their game by updating them with the latest skills required to complete their tasks efficiently in order to sustain in this highly competitive atmosphere driven by digitalization (Rykun, 2019). Employees are also required to possess the right skill and knowledge to carry out their respective jobs in the organization. Using $\mathrm{Al}, \mathrm{HR}$ personnel can help their employees not just identify training needs and provide timely and accurate training but can also identify the best career path for employees helping in developing in talent within the company sustainably (Arago Consulting, 2019). Using developments in e-learning platforms companies can provide personalized training with certain flexibilities on time, location, etc., based on the employee profile and their skills they aspire to have or develop (Wright \& Atkinson, n.d.).

\section{RESEARCH METHODOLOGY}

In this qualitative study, an in-depth interview was conducted to investigate on the applications, scope, benefits and challenges of Artificial Intelligence in Human Resources in the Indian context. A purposive sampling method was used to identify individuals with at least 5 years of experience in the HR function and also have been using $\mathrm{Al}$ as part of their function for at least 1 year. Respondents were not limited to any particular industry however the context for the research was narrowed down to India.

Telephonic, Skype and in-person interviews were used to extract data from the respondents through a semi- structured interview using the following interview questions as a base:

1. Have you found Al beneficial to the HR function?

2. In what area of HR is Al being currently used in your company?

3. What other HR function do you think Al would have a major impact in next?

4. What are the few distinct benefits you have reaped from using this technology?

5. What do you think are some of the limitations of Al with respect to the HR function?

6. How did you deal with the challenges you faced during the implementation of Al in HR?

7. What are the major possible reasons for integration or non-integration of $\mathrm{Al}$ in $\mathrm{HR}$ ?

Further explanations or clarifications were sought on a need basis. The responses from the respondents were based on their experiences and insights in the area of this research. The 8 respondents also belonged to different companies functioning out of different locations within India. The respondents have been addressed as R1, R2, R3, R4, R5, R6, R7 and R8 in the further discussions.

With the respondents' consent the interviews were recorded for the purpose of further analysis only for this particular study. The contents from the interviews were transcribed. The data was then analysed using thematic analysis to identify frequently mentioned themes, common keywords and patterns across the data that were related to the experiences of these individuals pertaining to the usage of $\mathrm{Al}$ in the $\mathrm{HR}$ function.

\section{FINDINGS}

The qualitative study focused on the subjective experience of HR professionals from Indian organizations using artificial intelligence in the human resources function. The participants shared their views and experiences about the various applications, benefits, challenges and limitations of integrating Al and HR within their organization. Following are the findings from the interview with the respondents, the themes and subthemes that emerged out of the analysis run on the data collected. 


\section{Figure 1}

Respondents who found Al beneficial to the HR function

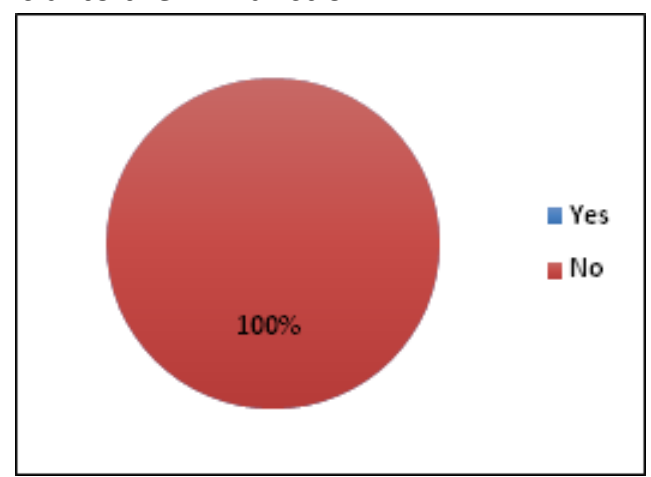

\section{Figure 2}

HR functions Respondents are currently using Al in

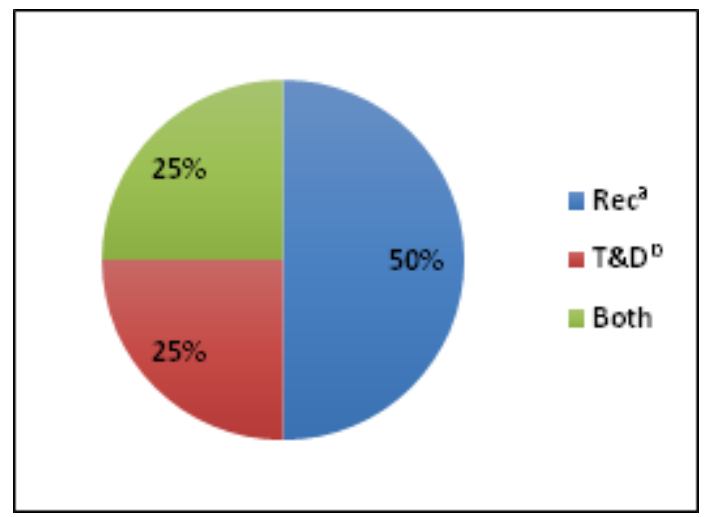

Note. 'Recruitment, 'Training \& Development

\section{Figure 3}

HR functions Respondents believe Al will impact next

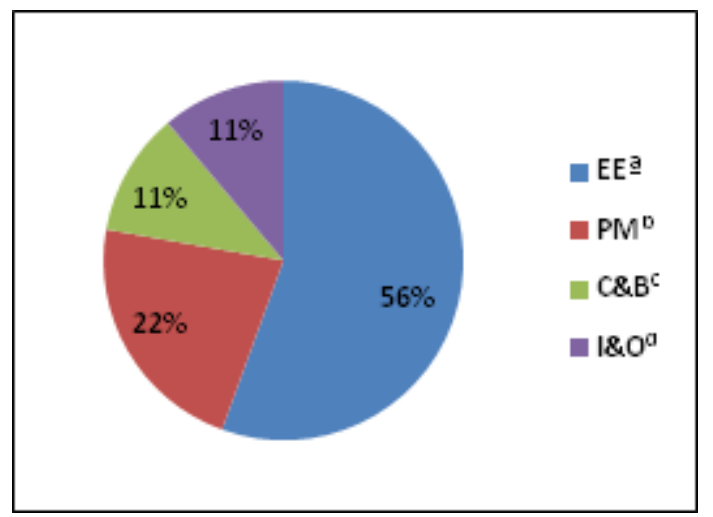

Note. 'Employee Engagement, 'Performance Management, 'Compensation \& Benefits, 'Induction \& Orientation

\section{THEME 1: RECRUITMENT}

According to 6 out of 8 respondents Al has proven to be a major supporting tool for efficiently and effectively recruiting ideal candidates for their companies. R3 said, "Earlier one of our main difficulties was finding the right candidate for our organization. We had lot of problems finding employees who will stay in the company for a long time and be productive as well. Often it would happen that we would hire well qualified employees in terms of qualifications and experience. However, since we were recruiting manually or based on our recruiters and interviewer's judgement alone, it left us open to a lot of bias and prejudice increasing the chances that the candidate selected would be incompatible with our company culture and policies. This percentage of recruiting incompatible candidates has significantly reduced since we started 
using Al powered platforms to source our candidates for employment. Now, although interviews are still a part of our recruitment process, the number of incompatible candidates being recruited every year has reduced to a great extent as the selection of candidates is more data driven and the decision to hire or not hire an employee is substantiated with the right data. As a result, we have been able to create a more efficient pool of candidates within our company which is also reflected in our bottom line."

Subtheme 1: Application Filtering. Respondents stated that they are using Al to also screen through a huge number of applications from multiple job portals. R4 said that, "Earlier we faced a lot of difficulties in just screening through the huge volume of applications we received for vacancies. This would a lot of man hours to go through and often caused delays in the recruitment process. A lot of people would just apply for the job irrespective of whether it matches with what has been mentioned in JD. We have also had people applying to a job in our company because of the company name or package or for various other reasons and this was also bad for the recruiters in our company as they would often miss their targets of closing candidates for jobs." The respondent also mentioned that, "Al does the same job of filtering applications for us but in a less time consuming and intuitive fashion as it is able to go through the applications at a much faster pace while assessing whether the candidate would be a right fit for the job. It also shortens the recruitment time by scheduling interviews with potential candidates."

Subtheme 2: Rediscovering Candidates. Hiring of qualified candidates who were previously rejected in an interview is also an efficient way of hiring good candidates in less time. Recruiters often feel that because of the high competition level many good candidates may end up applying for the job in one pool while there maybe incompetent candidates in the other. This mismatch may cause problems for the recruiter as finding highly capable candidates every single time is very difficult. R7 said, Al is great at keeping track of all the candidates who have applied for a particular job in our company. It is also able to make suggestions from a previously rejected group of well-qualified people when a similar job opening arises which in turn helps us to hire good candidates much faster than before and also saves us the cost of going through the whole process of recruitment every time there is a vacancy."

Subtheme 3: Multichannel Sourcing. 4 out of the above mentioned 6 respondents mentioned that, Al also helps them link multiple sources for the purpose of recruiting both internal and external. R1 stated, "Finding suitable candidates has never been this easy. Al just pools in the kind of candidates we want based on job descriptions and any other specific criteria required by our recruiters. Since multiple ways are used to look for candidates, the pool is much wider increasing the chances of finding the kind of candidates we are looking for. This simply gives us more options to choose from."

\section{THEME 2: TRAINING AND DEVELOPMENT}

The second aspect of HR where Al seems to have made its mark is the Training and Development function that focuses on providing training to candidates to improve their performance by improving their skills, behaviour and cultural fit to the company. 4 out of 8 respondents agreed that Al has not only helped them improve the content, course, schedule and delivery of the training but has also helped in increasing the overall engagement of the employees in the training programs. 3 of the above mentioned 4 respondents also said that, the Al based training enhanced the learning of the employees which was clearly through in their performance levels.

Subtheme 1: Customized/ Personalized Content. R2 said, "Each employee is different from the other. They all have their own individual learning pace, understanding capability, skill set, knowledge bank and likes and dislikes in terms of how a certain information is presented to them, etc. As an HR, designing training modules to suit all these different needs is always difficult. You are always looking to give the necessary information in the best way possible for the trainees to understand easily." The respondent went on to say, "This is why we use Al to ensure that each employee gets a very personalized experience. The Al tool is able to identify the level of the employee based on the results of the continuous assessment conducted at the end of every step in the training program."

Subtheme 2: Career Tracking and Development. Another key thing R1 said was, "Al makes career tracking of employees easier. Al makes this possible by combining the data that is collected on each employee from superiors, peers in the form of appraisal and the employee himself through feedback forms and surveys the employee fills out throughout his course in the company, training courses the employee has shown interest in, career path details, etc. The Al then analyses this data and helps in creating career goals that are achievable yet challenging for employees. It gives a proactive image to the HR that also keeps the 
employees happy and satisfied with their development needs." 
Subtheme 3: Real-time Suggestions. Al supported Training sessions have also helped them track each employees progress during the training program providing them real-time data that helps them make real time suggestions. R8 said that, "The use of Al linked with our online internal learning system gives freshers joining our company the opportunity to learn everything about the machinery they are to operate after the training period is over through a simulation-based training module. During the training, the freshers are constantly suggested with videos, images, tutorials, etc., every time they make a mistake in operating the machine properly in the simulation. The same combination of system is also used for the other employees in our company for training on safety measures, importance of safety gears, and other such technical topics by creating interactive training modules fuelled by Al."

Subtheme 4: Employee Engagement. Earlier HR personnel would often be faced with the problem of engaging their employees in training sessions. R6 stated, "Al has helped in solving this problem to a great extent. The quality and diversity of the content available for training sessions is a lot more engaging than it was a few years back. Common problems faced while conducting trainings such as place, time, good trainer, etc., are solved using Al based interactive training programs that employees can access from anywhere, anytime. Al also has helped in delivering high quality training to employees at low budgets as most of the money intensive aspects are eliminated or replaced with much better means."

\section{THEME 3: BENEFITS OF USING AI IN HR}

Using Al powered systems, the respondents were able to gain a competitive edge by enhancing the quality of the most important resources that a company possess in the market which is 'Humans'. Major Benefits that the respondents were able to gain from using Al have been mentioned below.

Subtheme 1: Cost Reduction. 8 out of 8 respondents agreed that Al helped in reducing the costs they were incurring from different functions such as recruitment and training. R5 said, "Al is definitely not a cheap technology, it costed our company a pretty good amount to do the installations and train employees. However, since then we have managed to cut down our costs in terms of manpower invested solely for the recruitment process, cost of conducting training in specific locations, hiring trainers, recruitment cost, etc. Al gives you solutions that are highly relevant and effective through its analytical and forecasting prowess giving us a chance to prepare for the future problems better. This also helps in keeping your costs to the minimum."

Subtheme 2: Better Manpower Utilization.All 6 out of the 8 respondents who agreed that Al was supporting the recruitment of candidates in their respective companies also seemed to commonly state that $\mathrm{Al}$ has allowed them the freedom to re-allocate their manpower to more better tasks in the organizations than just screening applications from candidates. R7 said, "The employees showed signs of resistance initially, we had to go through a lot of training and career guidance talks to ensure that we did not lose our HRs especially the recruiters. It also required us to create new job roles and restructure to accommodate or shuffle the employees. However, the whole thing turned out to be good for both the company and them as we were able to solve our problems using $\mathrm{Al}$ and they were able to contribute more to the company and add more value to their work. The job satisfaction of employees in the HR function has also gone up as they are into more challenging roles rather than a monotonous one."

Subtheme 3: Time EfficientThe next important benefit the respondents said they achieved from using Al was 'Time'. R6 said, "It's simple, 'TIME is MONEY'." Every delay in the productivity of the company caused as a result of employing incompetent employees is the HRs fault and he should be responsible for it. Also, the time taken to remove the incompetent employee from their position and refill it with a more competent employee which was actually a result of the bad hiring is also accounted to the HR. The time thus invested in solving these problems may convert to losses for the company and reflect on their bottom line." R1 mentioned, "Everything is faster and much more time saving with Al. It also makes it easy for the HR to manage their time well. Irrespective of the function, whether recruitment, training, employee engagement or compensation or one of the other functions. Al gives you a lot more flexibility with regards to the time. For example, Recruitment processes become faster, employees can partake in trainings in their own pace and so on. It not just saves time but also is effective in the fact that it helps in getting work done at a much better pace.

Subtheme 4: Job Satisfaction.Job satisfaction is the most important factor when it comes to deciding whether an employee will stay or leave the company. Job satisfaction could be driven through various elements such as compensation, rewards, workplace culture, workplace relationships and so on. R4 stated, 
“Attrition tracking using Al helps us identify potential quitters in the company by tracking employees' 
reviews, feedbacks, absenteeism rates, and other factors. We are able to address these employees and find out the reasons for their dissatisfaction. This gives a chance at recognizing patterns or common reasons and take the necessary measures to resolve it. Employees nowadays are also focusing on elements other than money when it comes to working in any organization. Sometimes, the problem could be in a workplace policy, a problematic manager, mismatched targets or some other reason. Resolving issues promptly has helped us keep our employees' job satisfaction levels high which also reduced our attrition levels."

\section{THEME 4: CHALLENGES}

Subtheme 1: Mindset.One of the major challenges of HR while implementing Al in the HR function is the mindset of the employees. R3 said that, "there is a slow yet steady growth in the positiveness among the HR professionals in India towards the concept of integrating AI and HR. However, the major cause for the delay in adapting the technology successfully has been the lack of knowledge and understanding among HRs in India to the technology itself." The respondent believes that this is the reason why there has been a negative mindset among the HR personnel in India.

R8 believes that the negative mindset is also fuelled by the general notion among people that Al will replace HR in companies. He said, "Obviously we are slow to adapt the change. We have always seen Al and HR commonly spoken about as 'Al Vs HR' or 'Will Al replace HR in the organization' rather than understanding that both are in fact interdependent to achieve higher performance and results."

Subtheme 2: Eliminating Bias.Another major challenge is the elimination of bias, although Al systems are designed to eliminate any form of bias or prejudices it is still difficult to eliminate bias from HR processes. R4 stated that, "Al analyses past data for learning and then produces insights. It is possible that a certain pattern maybe present within the past data in the form of unconscious bias."

Upon further questioning about what he meant by unconscious bias the respondent explained, "The Al while running the analysis may find that attrition among men in the company has been increasing in recent years. Based on this data the Al may form a bias against men causing it to select only women candidates from a pool of resumes. The reason however could be that the number of male hires in the company also increased during the same period. The Al systems are capable of learning on their own as they are created to think like us (humans). Therefore, in HR the Al is also susceptible to errors similar to the ones HR personnel and recruiters make making it a challenge for HR while implementing the Al systems."

Subtheme 3: Ethical Issues.Ethicality of the usage of Al is also a challenge HR faces in organization. R6 said, "Generally, employees are sceptical of Al because of its highly pervasive nature that enables it to track and monitor multiple aspects of employees behaviour. Therefore, employees as well as HRs need to be educated in order to understand the various ethical issues involved in the process of collecting employee data and using it to for company purposes. The clear line of ethical and moral values should be established and both the HR and the employees should be educated and made aware of the implications of crossing the line before using the technology for any purpose which will make the transition easier."

\section{THEME 5: LIMITATIONS}

Although Al solves a lot of problems in HR it still has its limitations just like any other technology in the market. Irrespective of how the benefits of integrating Al into HR may outweigh the limitations they still cannot be ignored. Common themes that emerged from asking the respondents about what they thought are the possible limitations of Al with regards to the HR function are as follows:

Subtheme 1: Accommodating Anomalies. According to R3 who specializes in using Al in the recruitment function one of the major limitations was the inability of Al to accommodate anomalies in the resumes of the candidates applying for the job. The Al systems have been seen to reject qualified candidates because of some unexpected elements in the CV. Formatting of the CV, Design, Font, etc., that do not fit the norm could considered as the factors for eliminating potentially good and qualified candidates from the recruitment process. So, although Al is highly powerful and effective it is not perfect as it is still going through its learning curve with regards to the HR practices.

He also said, "We have also had candidates who somehow got selected based on the keywords mentioned in their CV even though they were not an ideal fit for the job. This aspect of candidates morphing their resumes is also undetectable by the Al systems. Now, practically this necessarily may not make a lot of difference to the company since the success rate is still higher. Also, for companies who are able to employee high quality employees for fine tuning the Al systems could overcome this limitation with more 
intuitive programs that might come into play in the future. 
Subtheme 2: Contextual Understanding. Artificial Intelligence is designed to only draw insights from analyzing past data. "If you evaluate all your leaders and they happen to have size 9 shoe, does that mean you only recruit people that have a size 9 foot? Al and machine learning will tell that is all you should do. So, you have to add a contextual element to the data analytics," said Ryan Ross in a meeting on the role of $\mathrm{Al}$ in talent acquisition. Al is only capable of crunching big data to provide the HR with data that shows a pattern. However, it is imminent that decisions taken by the HR should also be based on practicality and good judgement keeping in mind the context of the problem in order to facilitate effective problemsolving.

\section{DISCUSSION}

This qualitative study was undertaken with the aim of exploring the status of Artificial Intelligence in Human Resource Management in the Indian context. Based on the analysis two major themes and corresponding subthemes were realized based on the experiential responses from the respondents. The research saw a positive result that brought to light that companies in India are catching up with the rest of the world by slowly moving towards the integration of artificial intelligence into their respective HR functions. The 20192020 research report by the State of HR Technology India shows that $70 \%$ of the firms conducting business out of India have turned to automation of recruitment, communication, performance management, collaboration and other such operational activities (Tanwar, 2019). The article also mentions that in these companies only parts of the HR function have been integrated with Al and only very few companies have integrated $\mathrm{Al}$ into all their HR functions drawing out its maximum potential.

Our results from our research also seem to be in line with this article as the findings showed that only $25 \%$ of the respondents are using $\mathrm{Al}$ in more than one function while few of the respondents revealed that they are looking to integrate $\mathrm{Al}$ into the other HR functions in their respective companies by the end of this year. This means that the number of functions being integrated with $\mathrm{Al}$ is increasing gradually and we can expect to see a greater level of Al integration into other HR functions such as Employee Engagement, Induction and Onboarding, Compensation and Benefits, Performance Management and so on.

The primary finding from this research was that the HR function where most of the companies are using $\mathrm{Al}$ is Recruitment. The statistical findings from this research shows us that $50 \%$, i.e., 4 out of 8 respondents are using it solely for recruitment. Also, it is notable that the respondents belong to companies across various industries functioning out of India that are using Al in their HR functions and not recruitment agencies or companies whose sole purpose is recruitment of talent for other companies. The companies to which these respondents belong are using Al majorly to reduce the amount of manpower invested in the screening of candidates for recruitment purposes and also the time involved in selecting a potentially good candidate.

Another reason for companies using Al majorly in recruitment is its ability to collect data from various sources to predict potential exiters from the company. Predicting employee turnover gives HR and edge in reducing the time required to fill the vacancy effectively with a potentially good candidate. Identifying potential exiters also allows the HR a chance to prevent the employee from exiting by understanding the reason behind it. This is very important for a company as losing good candidates to reasons that could have been possibly averted may ruin the company image and prevent new candidates from joining the company as candidates often do their research about the company before joining the company through various sources such as online reviews, employee feedback, etc.

The research also showed that the second area where $\mathrm{Al}$ is being used majorly is the Training and Development function with $25 \%$ of the respondents using it for this function. The respondents revealed that the use of $\mathrm{Al}$ for delivering designing and delivering content has had a significant effect on their employee engagement levels. The flexibility of Al to integrate different forms of media such as image, audio, video etc., and the possibility of using game mechanics to create innovative training modules helps them deliver more personalized and creative content. Also, the interactive design of the training helps keep the employees engaged continuously and improves their learning process with regards to the content. Another major benefit of using Al for training purpose was that employees could access the training from any place and at any time as companies can deliver the training over their website, mobile apps and other such mediums. The responses from respondents also reveal that there is a significant difference in the employee performance for the better after switching to Al based training programs.

The study shows that there is high potential for the Al technology to influence the Employee Engagement function. However, developing content that is highly creative and engaging is not easy as variables such as purpose of the module, employees' preferences with regards to the content, the form of game mechanics 
and many more need to be considered. Although this may seem like a drawback, it actually gives scope for newer 
HR roles that urge HR personnel to be more creative and innovative in their approach. This kind of nurturing will also help these HRs to develop skills required to solve future problems more creatively and efficiently as they develop into HR leaders who will play a key role in strategizing for the company.

The integration of $\mathrm{Al}$ into the HR function is a positive move for companies. However, the path to integration is difficult and has its own set of challenges that the HR will have to deal with while integrating $A l$ and HR. The biggest challenge respondents mentioned in integrating $A l$ into HR is the mindset of the HR personnel which is a result of the knowledge they have accumulated over the years and the resulting beliefs. They also believe that, the influence of media such as articles, movies, videos, etc., is huge in tuning the mindset of people. It is seen that still many forms of media readily available to the public portray Al as a substitute to human efforts rather than a tool to enhance the human experience in organizations (Gandhi, 2017).

Also, many employees seem to be doubtful about Al because its highly pervasive capabilities. For example, what if the technology is used by the company to track employee behaviour and activities outside of the organization to identify factors that may be hampering their performance. Although such a data may be highly beneficial to the HR, monitoring employees' personal activities is a breach of privacy which is extremely unethical. This problem can be addressed by creating clear cut policies that guide the usage of such technology and the repercussions of misusing said technology for unethical purposes. Therefore, the HR managers need to take up efforts to ensure employees that the technology is safe and ethical to use. The HR should also educate their personnel regarding the pros and cons of using such a technology and more importantly help them understand how the integration can help them in developing into better HR employees and make meaningful contributions to the company and reap better rewards in turn. The fact that Al cannot replace HR in companies should be made clear to the employees. Al is a tool to enhance human capabilities to the maximum, this should be reinstated into their minds with real life examples of companies who have managed to make the most out of the technology.

Al technology also has its limitations with regards to its functionality and effectiveness in the HR function. The research revealed that even though $\mathrm{Al}$ is extremely efficient in terms of replacing manpower for sourcing candidates it is still vulnerable to bias that is similar to human bias. Being a heavily data driven technology, it is imperative that any data used for analysis should be validated and the accuracy of the data should be checked. The data should be validated based on certain metrics to ensure that there are no unconscious bias or counterproductive patterns in the data. Disparities in the data and the presence of missing values should be considered and there should be measures to make up for data lost in transmission.

Although having accurate data for the analysis will give the HR a better idea of the solutions and the possible factors that may logically solve the situation it cannot account for the anomalies and emotional aspects in sorting candidates. Therefore, it is the HRs responsibility to understand the context of the problem and take the emotional aspects of the problem into consideration as irrespective of the accuracy of the data, understanding candidate or employee psychology is too complex for any Al system (Artisan, 2017). HR managers need to take note of this limitation in order to create new opportunities for their personnel in areas that currently limit the Al.

The HR function could always use the Al's ability to identify patterns to keep track of the ever-changing needs and preference of their employees allowing them to stay one step ahead. Also, being able to forecast and predict future events helps the HR function to be a better strategic partner to their organizations making them highly impactful contributors in realizing the organizations goals and objectives effectively by driving a more efficient pool of employees.

\section{HR IMPLICATIONS}

Following are few HR implications for companies considering to integrate Al and HR based on the findings and insights from the research.

\section{IDENTIFY PURPOSE FOR INTEGRATION}

Implementing Al systems into the HR functions for the sake of dealing with competition is a bad move for any company. Companies need to identify and narrow down the specific purpose or problem they are looking to solve before integrating Al.as it would be difficult to identify the right technology that would help in solving the problem otherwise. Companies need to identify the function they are looking to integrate, the extent of integration and the resource constraints of the company before selecting the Al software. 
For example, in the recruitment function, there are several Al software available in the market that carry out different activities within the realm of recruitment. Resume screening, Applicant Tracking, Candidate Testing, etc., are all examples of activities carried out by different Al software. There are Al software that also provide a multitude of applications as a package. Therefore, identifying the purpose for integration and the constraints of the company would help them realize which Al program would be the most effective in solving the HR problem faced by the company.

\section{IDENTIFY BARRIERS}

Artificial Intelligence and Human Resource are often considered as oxymorons by employees. For HRs looking to integrate Al with their HR functions one of the key steps would be to identify the possible barriers that may prevent or hinder the transition. Since employee mindset is the most important factor that may decide the success of the integration, HR managers need to ensure that their personnel are on the same page as the organization. The personnel should be made aware of the benefits they may reap as a result of the integration and how Al will make it easier for them to perform their jobs more efficiently. Employees should also be aware of the potential job roles that may be created in the organisation as a result of the integration and how the company is going to help them in transitioning into the new job roles effectively.

Companies need to help employees see $\mathrm{Al}$ as a tool to increase their performance rather than as a threat to their jobs. The mindset of Al vs HR should be changed to Al and HR.

Another barrier companies face is in terms of the resources available with the company to aid the integration. Companies need to ensure that they also have the financial and infrastructural capabilities to support the Al systems along with other resources required to integrate Al into the HR functions. It is important for the HRs in companies to reduce the resistance and barriers within the company in order to successfully integrate Al and HR.

\section{DEVELOP HR PERSONNEL}

Companies who implement $A I$ into their HR functions without equipping their personnel with the right knowledge and skills will face problems in using the technology effectively. Companies need to provide proper training to employees before the implementation in order to impart all the necessary knowledge and skills required to not just use the Al tools effectively but also troubleshoot problems that may arise during the usage of the technology. Companies should take steps to make sure that the HR personnel who will be using the technology are equipped with the skills before the integration rather than taking up a learning on the go approach. Having enough knowledge and the right skills prior to the integration helps employees spend less time on troubleshooting and more time on solving organizational problems and making full use of the technology.

Most importantly, Al softwares only provide insights and predictions based on analysis of historical data. These predictions or insights cannot be used for decision making purposes directly. Not all suggestions made by the Al softwares after running the analysis may prove to be relevant and practical, and within the constraints of the company. Employees should be trained to understand the context and relevance of the results to the problem faced by the HR function or the company in order to make effective decisions that would impact the company for the better.

\section{REALIZE POSSIBILITIES}

Artificial Intelligence is one of the most versatile technologies in this era. Still, most of the companies in India are using Al in their HR functions to handle only one function with very few companies integrating multiple HR functions with Al. The technology has proven its utility in multiple HR functions such as Compensation \& Benefits, Employee Engagement, Induction \& Onboarding, etc., in many countries in the world.

HRs in India need to be open to exploring the various possible applications of Al and the different benefits it may provide to the organizations. For example, in the Compensation \& Benefits functions, Al can be used to achieve fairness in compensation. A survey conducted among the 10 biggest tech companies with 4000 plus employees revealed that only $45 \%$ of employees who were highly compensated felt they were fairly paid. Al systems can be used to identify behavioural patterns among high performers and relate them to compensation packages given in the past to outline the criteria for compensation. This helps in eliminating bias in compensating employees while establishing fairness of pay (Kulkarni, 2020). 
Similarly, there are multiple ways in which Al can be applied to different functions of the HR domain. Integrating more HR functions with AI may prove to be highly beneficial for companies as it may increase overall managerial efficiency and improved decision making in multiple facets of the HR function.

\section{CONSIDER LIMITATIONS}

Although Artificial Intelligence sounds like a fix it all solution to HR problems, just like any other it has its own limitations. Based on the research it is seen that Al systems are still incapable of fully understanding emotional aspects involved in the decision-making process. Results produced by Al systems are highly logic driven and therefore, some of the solutions suggested by the Al systems may not be applicable to the situation of the company and other several constraints.

Another limitation to be considered is Als ability to identify unconscious bias from data used for analysis. Being a technology that thrives on data, $\mathrm{Al}$ is open to making mistakes as a result of errors and disparities in the data. Therefore, HR functions need to make sure that the Al systems are programmed to address missing values in the data and measures should be taken to avoid the emergence of any unnecessary bias by validating the data prior to running the analysis.

\section{CONCLUSION}

The study revealed that the integration of $A I$ into the HR functions in Indian companies has been relatively less compared to businesses from other countries. Currently, Al is being used in other HR functions such as Employee Onboarding, Employee Engagement, Employee Compensation and Benefits and Employee Rewards and Recognition throughout the world however in India the penetration into these functions is relatively low. The two major areas where Al has the highest involvement in India are the - Recruitment and Training \& development functions of HR. The study also showed that the involvement of Al in the HR department of companies in India was considered less pervasive as compared to the other domains within the organization such as Marketing, Finance, Production and others. This was addressed to be a result of the lack of knowledge imparted to HR professionals regarding the benefits and opportunities created through the integration of Artificial Intelligence into HR which in turn has created barriers in the minds of people, preventing them from seeing how Al could actually bring about a positive change within the HR function and support its role of playing a strategic partner to the company.

The research also brought to light other themes such as - the common challenges HRs might face while integrating $\mathrm{Al}$ and $\mathrm{HR}$ and how these challenges could be overcome, and the limitations of the technology in its current state and most importantly the benefits of using such a technology in the HR function. The study looked to acquire more knowledge regarding the concept of artificial intelligence in the human resources function in the Indian context in an attempt to guide upcoming HR personnel in adapting to a more technologically sound $H R$ function.

Thus, this qualitative research has found that Al and HR are no more oxymorons. Although the progress in the area of merging Al and HR is lagging in India, the opportunities and tools to catch up are available and it is only a matter of spreading the awareness regarding the transformational benefits Al for HRM. Overall, the research has shown that the merger of AI and HR is a positive affair that HR professionals could use it to increase their impact in the organization by enabling them to act as strong strategic partners.

\section{REFERENCES}

1. Arago Consulting. (2019, April 26). HR challenges - Artificial Intelligence, Process Automation and HR Chatbot. Retrieved from https://www.aragoconsulting.eu/en/tips-best-practices/6-biggest-challenges$\mathrm{hr}$ - function-2019-artificial-intelligence-process-automation-hr-chatbot

2. Artisan. (2017, September). FINDING AND SOURCING EMPLOYEES IN THE DIGITIZATION ERA. Retrieved from https://cdn2.hubspot.net/hubfs/1951043/Content\%200ffers/Ai_Whitepaper/Artisan\%20Talent\%20Al\% 2 0and\%20Bots\%20in\%20Recruiting\%20Paper.pdf

3. Cedric Villani. (2018, March). WHAT IS ARTIFICIAL INTELLIGENCE? Villani mission on artificial intelligence. Retrieved from https://www.aiforhumanity.fr/pdfs/MissionVillani_WhatisAl_ENG(1)VF.pdf

4. Davenport, T. (2019, February 11). Al And HR: A Match Made In Many Companies. Retrieved from https://www.forbes.com/sites/tomdavenport/2019/02/10/ai-and-hr-a-match-made-in-manycompanies/\#71bcdc983cd3 
5. Dinah Wisenberg Brin. (2019, March 19). Employers Embrace Artificial Intelligence for HR. Retrieved from https://www.shrm.org/resourcesandtools/hr-topics/global-hr/pages/employers-embraceartificial- intelligence-for-hr.aspx

6. Emily He. (2019, April 3). The Advantages of Re-Humanizing HR with Artificial Intelligence. Retrieved from https://www.hrtechnologist.com/articles/digital-transformation/the-advantages-ofrehumanizing-hr-with-artificial-intelligence/

7. Erika Rykun. (2019, December 3). Artificial Intelligence in HR Management - What Can We Expect? Retrieved from https://thebossmagazine.com/ai-hr-management/

8. Ernst \& Young. (2018). The new age: artificial intelligence for human resource opportunities and functions. Retrieved from https://www.ey.com/Publication/vwLUAssets/EY-the-new-age-artificialintelligence-for-human-resource-opportunities-and-functions/

9. Folick, O. (2016, October 17). Al For Recruiting: A Definitive Guide For HR Professionals. Retrieved from https://ideal.com/ai-recruiting/

10. Geetha R, \& Bhanu Sree Reddy D. (2018). RECRUITMENT THROUGH ARTIFICIAL INTELLIGENCE: A CONCEPTUAL STUDY. International Journal of Mechanical Engineering and Technology (IJMET), 9(7), 6370.

11. HR.com. (2017). The State of Artificial Intelligence in HR. Retrieved from https://harbingersystems.com/wpcontent/uploads/2017/12/WP_StateofArtificialIntelligenceinHR_HarbingerSystems_112717.pdf

12. James Wright, \& Dr David Atkinson. (n.d.). The impact of artificial intelligence within the recruitment industry: Defining a new way of recruiting. Retrieved from https://www.cfsearch.com/wpcontent/uploads/2019/10/

13. Jyoti Kapoor. (2020). Understand The Role Of Al In HR in 2020. Retrieved from https://www.cutehr.io/ai-in-hr/

14. Maria Aspan. (2020, January 20). A.I. is transforming the job interview-and everything after. Retrieved from https://fortune.com/longform/hr-technology-ai-hiring-recruitment/

15. Mason Stevenson. (2019, September 11). Al in HR. Retrieved from https://www.hrexchangenetwork.com/hr-tech/articles/ai-in-hr

16. Tadapaneni, N. R. (2017). Artificial Intelligence In Software Engineering. Available at SSRN 3591807 or doi: $10.2139 /$ ssrn.3591807

17. Mellam, A. C., Rao, P. S., \& Mellam, B. T. (2015). The Effects of Traditional and Modern Human Resource Management Practices on Employee Performance in Business Organisations in Papua New Guinea. Universal Journal of Management, 3(10), 389-394. doi:10.13189/ujm.2015.031002

18. Meister, J. (2019, January 9). Ten HR Trends In The Age Of Artificial Intelligence. Retrieved from https://www.forbes.com/sites/jeannemeister/2019/01/08/ten-hr-trends-in-the-age-of-artificialintelligence/\#3993dcec3219

19. Nicolaus Henke, Jacques Bughin, Michael Chui, James Manyika, Tamim Saleh, Bill Wiseman, \& Guru Sethupath. (2016, December). The age of analytics: Competing in a data-driven world. Retrieved from https://www.mckinsey.com/business-functions/mckinsey-analytics/our-insights/the-age-of-analytics

20. Nigel Guenole, Ph.D., \& Sheri Feinzig, Ph.D. (2018, November). The Business Case for Al in HR With Insights and Tips on Getting Started. Retrieved from https://www.ibm.com/downloads/cas/AGKXJX6M

21. Oswal, N., \& Narayanappa, G. (2015). Evolution of HRM to E-HRM to Achieve Organizational Effectiveness and Sustainability. International Journal of Business Administration and Management Research, 1(2), 22. doi:10.24178/ijbamr.2015.1.2.22

22. Owais Ahmed. (2018). ARTIFICIAL INTELLIGENCE IN HR. International Journal of Research and Analytical Reviews (IJRAR, 5(4), 971-978. http://www.ijrar.org/papers/IJRAR1944797.pdf 
23. Prasad Kulkarni. (2020, January 17). The Impact and Potential of Al in Compensation \& Benefits. Retrieved from https://sightsinplus.com/practices/rewards/the-impact-and-potential-of-aiin- compensation-benefits/

24. PWC. (2017). Artificial Intelligence in HR: A No-brainer. Retrieved from https://www.pwc.at/de/publikationen/verschiedenes/artificial-intelligence-in-hr-a-no-brainer.pdf

25. PWC. (2018, February). Artificial intelligence in India - hype or reality Impact of artificial intelligence across industries and user groups. Retrieved from https://www.pwc.in/assets/pdfs/consulting/ technology

26. Neelie Verlinden. (2019, November 18). 9 Intriguing Uses of Al in Recruitment in 2019. Retrieved from https://harver.com/blog/ai-in-recruitment-2019/

27. Richard D. Johnson, Hal G. Gueutal (2011). Transforming HR Through Technology: The Use of E-HR and HRIS in Organizations. Retrieved from https://www.shrm.org/hr-today/trends-and-forecasting/

28. Tadapaneni, N. R. (2019). Artificial Intelligence in Finance and Investments. International Journal of Innovative Research in Science, Engineering and Technology.

29. Tanwar S. (2019, August 7). Indian firms place faith in automation to drive down HR costs. Retrieved from https://qz.com/india/1682725/indian-firms-opt-for-ai-chatbots-to-automate-save-on-hr-costs/

30. Tutorials Point. (2015). Artificial Intelligence. Retrieved from https://www.dcpehvpm.org/EContent/BCA/BCA-III/artificial_intelligence_tutorial.pdf

31. Vaishnavi J. Desai. $(2019,5)$. Al not gaining ground in HR functions: Arvind Gupta of KPMG explains. Retrieved from https://cio.economictimes.indiatimes.com/news/strategy-and-management/ai-notgaining-ground-in-hr-functions-arvind-gupta-of-kpmg-explains/69659723

32. V. K. Jain. (2014). Impact of Technology on HR Practices. International Journal of Informative \& Futuristic Research, 1(10), 25-37. Retrieved from http://www.ijifr.com/pdfsave/13-06-2014621JUNEV10-E15.pdf

33. Tadapaneni, N. R. Artificial Intelligence Security and Its Countermeasures. International Journal of Advanced Research in Computer Science \& Technology, (2347 - 8446). 8. 10-12.

34. Wright, P. M., \& Ulrich, M. D. (2017). A Road Well Traveled: The Past, Present, and Future Journey of Strategic Human Resource Management. Annual Review of Organizational Psychology and Organizational Behavior, 4(1), 45-65. doi:10.1146/annurev-orgpsych-032516-113052

35. Sandeep Gandhi. (2017, May 18). Role of Artificial Intelligence in HR. Retrieved from https://www.pcquest.com/role-artificial-intelligence-hr/

36. Khanna, D. (2018). Use of Artificial Intelligence in Healthcare and Medicine. International Journal Of Innovations in Engineering Research And Technology.

37. Kamiyama, N., Nakano, Y., Shiomoto, K., Hasegawa, G., Murata, M., \& Miyahara, H. (2018). Advances and Analysis on Reducing Webpage Response Time with Effect of Edge Computing

38. McFadden C. (2019, August 20). 7 Ways Al Is Helping Revolutionize the Recruitment Industry. Retrieved from https://interestingengineering.com/7-amazing-ways-companies-use-ai-to-recruit- employees 